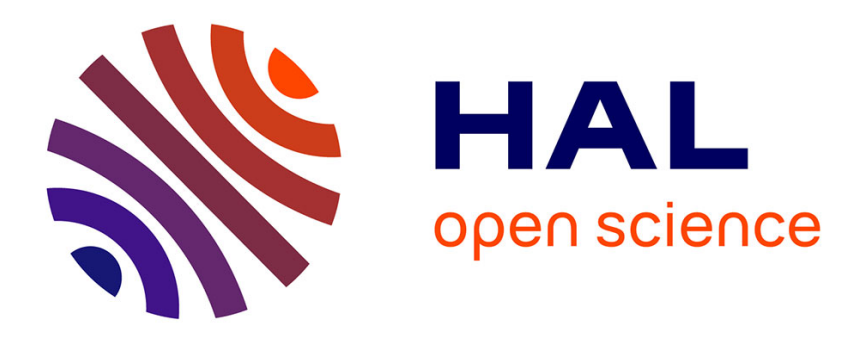

\title{
Operational Competence Management Comparison of Industrial Frameworks
}

Bernard Grabot, Raymond Houé

\section{To cite this version:}

Bernard Grabot, Raymond Houé. Operational Competence Management Comparison of Industrial Frameworks. INCOM'09, Jun 2009, Moscow, Russia. hal-00958855

\section{HAL Id: hal-00958855 https://hal.science/hal-00958855}

Submitted on 13 Mar 2014

HAL is a multi-disciplinary open access archive for the deposit and dissemination of scientific research documents, whether they are published or not. The documents may come from teaching and research institutions in France or abroad, or from public or private research centers.
L'archive ouverte pluridisciplinaire HAL, est destinée au dépôt et à la diffusion de documents scientifiques de niveau recherche, publiés ou non, émanant des établissements d'enseignement et de recherche français ou étrangers, des laboratoires publics ou privés. 


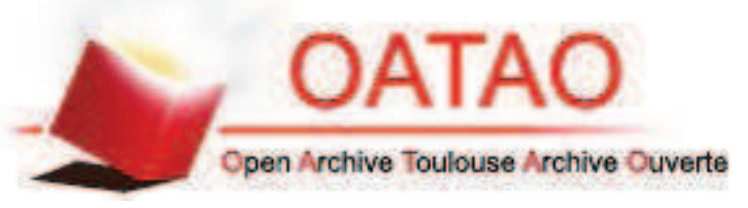

Open Archive TOULOUSE Archive Ouverte (OATAO)

OATAO is an open access repository that collects the work of Toulouse researchers and makes it freely available over the web where possible.

This is an author-deposited version published in : http://oatao.univ-toulouse.fr/ Eprints ID : 10935

To cite this version : Grabot, Bernard and Houé, Raymond Operational

Competence Management Comparison of Industrial Frameworks. (2009) In:

INCOM'09, 03 June 2009 - 05 June 2009 (Moscow, Russian Federation).

Any correspondance concerning this service should be sent to the repository administrator: staff-oatao@,1istes-diff.inp-toulouse.fr 


\title{
Operational Competence Management Comparison of Industrial Frameworks
}

\author{
Bernard Grabot, Raymond Houe \\ University of Toulouse, LGP - ENIT \\ 47 avenue d'Azereix, BP 1629 \\ 65016 Tarbes Cedex, France \\ (e-mail: \{bernard,rhoue\}@enit.fr)
}

\begin{abstract}
Competence management is a quite recent but important topic addressed by nowadays companies for improving their organization. With examples coming from several industrial projects, we show the difficulty of defining a consistent competence management framework, and exhibit the inconsistencies which can result from an insufficient analysis of this domain. Some guidelines are suggested in order to improve the quality of a Competence Management System.
\end{abstract}

Keywords: Competence management, qualification, workforce, organization.

\section{INTRODUCTION}

It is now clear for nowadays companies that Human Resource is a key competitive advantage, if its characteristics are better formalised and taken into account in the organisation. With a more operational point of view, one of the interesting novelties of the version 2000 of the ISO 9000 standards has been to push the companies to justify the competence of the people involved in their business processes. As a consequence, most of the large companies presently conduct projects aiming at structuring the competences of their employees, with the double idea to better allocate tasks to persons, and to provide a suitable framework for allowing these competences to grow up.

A software aiming at facilitating competence identification, structuring and use has been developed and was described in (Houe and Grabot, 2006). In comparison with the numerous competence management modules available on the market, this software focuses on operational competence management (and not on careers), and is based on a very flexible competence framework allowing to adapt its implementation to the requirements of each company. After six implementations of the software in companies from various sectors, we have noticed misunderstandings of the bases allowing to define a consistent competence management framework, able to provide an efficient support for improving business processes.

The rest of the communication is structured as follows: a brief state of the art on how human resource has been considered in industrial companies is firstly provided. The main characteristics of the Competence Management software which is the base of the study are described in section 3, and a short description of the companies in which the software has been implemented is provided. Various problems are exhibited in section 4 , and guidelines for a consistent definition of competences are suggested.

\section{HUMAN RESOURCE IN BUSINESS PROCESSES}

\section{From qualification to competences}

The qualification model is one of the earliest approaches promoted to cope with human resource in industrial organisation. With the basic objective to check that only trained people perform a given operation, it is supported by the idea that there is a stable relationship between individual capacities, processing time and workstation. Based on a "Fordian" view of the industrial manufacturing, it has for instance been used to define minimum salaries (Paradeise et al., 2001). The necessity to manage higher levels and more global skills, susceptible to give flexibility to the manufacturing systems, has resulted in the 80 's in the emergence of the competence model. Instead of assessing a worker by its ability to perform pre-defined activities related to an operation or a workstation, it consists in characterising an actor by the set of competences he holds and can set to work (Zarifian, 2002). Improvement of the individual efficiency, decrease of turn-over and improvement of technical competences are the main goals identified in (Wustermann, 2001) by companies that promote a competence approach.

Most of the projects launched in companies on Competence Management aim at identifying the available competences and develop them for facing the expected evolution of the companies core business. Therefore, a distinction is usually made between the competences held by an actor and those required by the activity (Franchini et al., 1999; Harzallah and Vernadat, 1999).

Competence is based on knowledge and experience, but also on behaviours allowing to make knowledge and competence operational in work situations: (Pilbeam et al., 2002) distinguishes technical and behavioural competences, similar 
to the "hard" and "soft" competences introduced in (Mc Clelland, 1973). Competences can be analysed at an individual level, gathering all the techniques capable of facilitating the emergence, the maintenance, and the development of personal competences (Amherdt et al., 2000), at a collective level (Vaudelin, 2002), or even at an organisational level (Sanchez et al., 1996).

An appropriate way of defining how competences can be deployed in an industrial process may require an intermediary step which can be provided by the concept of role. Organisations can be seen as systems of interacting roles (Katz and Kahn, 1996), where roles are considered both as sets of activities or expected behaviours.

\subsection{Competences in industrial performance optimisation}

A recent survey on how competences can be formalised and used for performance improvement can be found in (Boucher et al., 2007), showing that competence models may be of interest in all functions of various sectors (design, manufacturing, service...). Indeed, a number of software, dedicated or included in ERP (Enterprise Resource Planning) solutions, have appeared on the market for facilitating competence identification, structuring, use and development. These modules often have quite similar functions, allowing to list the competences required by a position, job or activity, and to manage the evolution of these competences through time using trainings. Nevertheless, the underlying frameworks of these modules are usually rather rigid, and require that the companies adopt a given "competence model". This is often rather difficult, since the Human Resource Departments of the large companies have already formalised competences frameworks for a long time, for instance for facilitating hiring or management of turnover. Taking note of that, a flexible framework has been described in (Houe and Grabot, 2006) and has provided the methodological base for the development of a new OpenSource software. The bases of this framework are described in next section.

\section{A REFERENCE FRAMEWORK FOR COMPETENCE MANAGEMENT}

The basic idea of a competence-based task allocation is to link people to tasks in a way which optimises a complex (but often implicit) objective function gathering quality (the person will do a good job), cost (the person has the lowest hourly rate) and delay (the person will do the job quickly). If the criteria allowing to assess the objective function are already defined, allocating persons to tasks becomes an optimisation problem which can be solved by various methods (see for instance (Kadrou and Najib, 2008)). Our study focuses on a previous stage, the definition of a framework allowing to quantify who can do a task (is the person enough qualified?) and at what cost (is the person overqualified?). In that purpose, we distinguish between competences hold by people and competences required by tasks, activities or roles. The corresponding concepts are defined in next sections.

\section{Competences}

Competences describe the various skills required for performing a task. A competence can be defined by a generic "quality" (e.g. "having good communication abilities"), but also by the ability to use a resource (e.g. "ability to drive a car"). A competence can be required or possessed at different levels. We do not set any constraint on the number of levels or on the way they are identified and labelled (numbers, text...).

\section{Trades and roles}

A set of competences may be commonly required to carry on a trade (ex. mason, carpenter, engineer...). In some cases (especially at decisional levels), such set of competences will not really define a trade but a role in a business process (financial manager, technical expert, user representative...). Trades and roles can be practiced at different levels, each level being defined by different requirements on the levels of the corresponding competences. Again, no constraint is set on the number or label of these levels.

\section{Enablings}

Performing some specific types of tasks (usually, dangerous or difficult) may require a specific training, resulting in the provisional recognition of a competence: e.g. driving a trolley, act on low/high voltage installations, etc. Usually, an enabling is linked to a trade, but other types of enablings may also be required: for instance, in the industry, each shift should include a first-aid worker, and a given number of volunteer firemen should be present in a company at each moment. Clearly, these enablings are not related to trades but to people, therefore, we have considered them as "personal enablings".

\section{Working situations}

Working situations can be linked to people with different granularity levels. Let us consider that the working situation is described by a business process composed of activities. First of all, abilities of persons can be associated either to the whole process or to activities, or even sub-activities of this process. Similarly, the ability required from the workforce can be defined by a level in a trade or role ("expert on dependability, level 3", "mason, level: expert"). If all the competences included in the trade or role are not required, listing only the required competences will provide flexibility, but necessitates a more precise description of the activity.

It is interesting to notice that personal enablings are not strictly speaking linked to a business process, but act as constraints on the set of persons performing activities during a given interval of time, in a given place.

\section{Trainings}

When a negative gap is noticed between the competences possessed by a person and those required by his (her) trade, role, task or activity, trainings should be suggested in order to 
fix the problem (this is what is required in the ISO 9000 norm: gaps are possible but ways to detect them should be defined, so that means to fix them). When a positive gap is noticed, two cases may occur:

- The person may be overqualified (the person has level 2 while only level 1 was required). Therefore, the allocation of this person to the task represents an extra cost.

- A second possibility is that the person holds the competences at a higher level than required by the level of his trade. This denotes a recognition problem which is the origin of many conflicts between employees and employers.

\section{IMPLEMENTATION IN SIX COMPANIES}

Some bases on the software implemented in the companies will firstly be given, then the main differences between the six implementations will be shortly described.

\section{The software}

The software which allows to implement these concepts has been described in (Houe and Grabot, 2006). It is accessible by Internet and provides generic features like comparison between required/possessed competences through different types of graphics, alerts on enabling run out, etc.. Nevertheless, its implementation requires a configuration phase consisting in the following steps:

- definition of the competence-types, regarding the "objects" on which the competence points,

- definition of the number of levels and labels of the competences,

- definition of the trades and roles,

- definition of the structure which allows to link competences and trades / roles,

- definition of the trainings,

- definition of indicators allowing to assess the quality of the competence system.

This methodological framework has been applied in the following six companies, the software being also implemented in five of them .

\section{Company $A$}

Company A is a SME manufacturing customised envelopes with complex printings and various shapes., Only a simple model has been implemented in the company. Different types of competences have been defined, namely knowledge, know-how and behavioural competences. Trades have been listed to cover the various activities required in the manufacturing process: handling, manufacturing, controlling, and packaging. Production is processed using complex automated machines performing sequentially all the operations of the routing. Competences could so be defined as the ability to use a machine, but the complexity of the task also depends on the manufactured product. Therefore, generic know-how competences related to manufacturing have been defined as the "ability to pilot machine $\mathrm{X}$ for product $\mathrm{Y}$ ".

\section{Companies $B$ and $C$}

Companies $\mathrm{B}$ and $\mathrm{C}$ are two factories belonging to the same group, manufacturing complex parts for the aeronautical industry, mainly through manual assembly.

In the aeronautical sector, a trade is a necessary but not sufficient condition for performing an assembly operation on the product: a specific training is required, and has to be regularly renewed. The companies have chosen to distinguish between "classical" competences linked to trades like assembler, controller, setter, etc. (named here trade_competences) and product_competences, linked to the assembly of a product. The typical structure of such product competences is "assembly of component $\mathrm{X}$ on product $Y$ using resource $Z "$ ". Concerning the structure of the competence system, trade_competences were directly linked to persons, and not to trades.

One of the goals of the competence system is to be sure that when an operation is to be performed, a competent worker will be available in the factory: detection of product_competences only hold by few persons was so a first objective of the competence management system. The dual objective was to detect persons who could only perform few operations, since these persons were supposed not to work if the operations were not processed during a given period.

It is interesting to notice that one of the factories had been only recently bought by the group: even if the project was supposed to homogenise the two competence management frameworks, this has not been fully possible because of the different cultures of the companies. Therefore, slightly different trades and competences were defined in the two factories.

\section{Company D}

Company D is a large company building complex electrical devices. The project focused on a business process dedicated to the analysis of the returned products. This process was involving different types of high level experts (on dependability, on design, on manufacturing...) which were scarce resources, to be managed very carefully. Therefore, the competence management framework was here oriented on the description of high level roles, each role being linked to a kind of expertise. Therefore, rather conceptual competences were defined, such as "capacity to generalise", "ability to disseminate the expertise", etc.

\section{Company E}

Company $\mathrm{E}$ is a local training centre of a worldwide company. The software was to be used for managing the employees of the training centre, but not the trainees. A rather complex structure was defined for the competence system: on one hand, the employees of the centre were coming from operational positions attached to four main sectors. On the other hand, the activity in the centre was defined through different types of job: administrative, trainer, quality manager... Finally, a position was defined by the combination of a sector and a job-type. Different competences were defined for the sector and the job, 
resulting in the definition of job_competences and sector_competences. These competences were grouped in several categories: generic, transverse, technical, pedagogical, etc. The centre asked for the possibility to make comparisons between required/hold competences at two levels: job and sector competences on one hand, these two comparisons being then aggregated on the position, after calculation of the average value of all the competence levels of the same type.

\section{Company F}

Company $\mathrm{F}$ is an association of small companies in the building sector. The defined trades correspond to usual ones, like mason, carpenter, etc. The corresponding competences are defined by national frameworks. A trade may be hold at four levels, corresponding to different coefficients for the salaries. Various types of enablings are also considered, including recent ones linked to the obtaining of eco-labels.

\section{DIAGNOSIS OF THE IMPLEMENTATIONS}

\section{Global results}

In all of the companies except A, technical skills or competences had already been formalised before implementation of the framework. Difficulties were mainly expected concerning behavioural competences, which may seem to set into question the persons, and not their technical skills, always subject to improvement. Surprisingly, the formalisation of the expected behavioural competences did not bring any social problem. Conversely, a worker in company $\mathrm{D}$ mentioned that this implementation at last allowed to make these criteria explicit, which was a progress for them.

In most of the companies, it has been chosen to assess the competences hold by employees through self-assessment first, then by the higher level. These two evaluations were to be compared during a debriefing meeting. The most important problem in that step was that many employees under-evaluated their competences. This fact can be interpreted by multiple reasons which will not be discussed here.

In one of the companies, the software was modified in order to keep trace of the three assessments (self-assessment, assessment by the higher level, final profile obtained after discussion).

As expected, the main results of the software implementation was the identification of inconsistencies in the definition of jobs and positions, and a better visibility of the gaps between what was needed and what was available in terms competences. The effort that the Human Resource department was spending on managing enablings and trainings was drastically decreased, allowing the department to work on more complex issues like careers, turn over and workforce motivation. The main drawback of the implementation was the huge amount of work required for gathering, then maintaining all the data required by the model. Clearly, this effort is only acceptable if there is a pay- back in terms of better control of the manufacturing quality and costs.

These successive implementations allowed us to learn much about the mistakes which can be done while defining the structure of a competence system. Some of these problems are discussed in the following sections.

\section{Definition of competences}

This is certainly the most difficult point of a competence project. A first important comment is that the aim of a competence management framework has to focus clearly on the management of "important" competences, which allow to differentiate people, make them critical resources and need to be preserved and developed. In all the companies, the first idea was implicitly to make an exhaustive list of all the competences used when carrying out an activity. The result is a great number of useless competences, hold by many people, and not related to any trainings. As a comparison, the average number of competences associated to a job varied from 15 for $\mathrm{B}$ and $\mathrm{C}$, were a focus was set on "critical" competences, to 50 in $\mathrm{E}$ and 60 in $\mathrm{F}$...

As stated above, the concept of "competence" should allow to cope with the combinatorial explosion resulting from defining "qualifications" related to elementary tasks. Nevertheless, relevant competences can only be defined after a conceptualisation which seem to be difficult in practice; therefore, we have noticed in nearly all the companies the presence of competences considered as the ability to perform a given task, e.g.:

- in Company E, competences like "ability to fill up form XXX",

- in Company F, nearly all the competences are directly related to task performance, e.g. for a mason "ability to build a wall", "ability to build a flag" etc. As a consequence, a usual trade like "mason" was defined by no less than 66 competences, which was clearly missing the objective of gathering elementary skills in generic competences,

Similarly, the so-called "product_competences" defined in Companies $\mathrm{B}$ and $\mathrm{C}$ are in fact linked to the execution of precise tasks, without any generalisation. Since these qualifications have to be managed, it was indeed better to clearly separate them from usual "trade-related" competences, even if the term "competence" was in our opinion inadequate.

Another possibility of confusion exists between enablings and competences. In Company $\mathrm{F}$ for instance, a competence was associated to each enabling: "holding enabling XX" was e.g. considered as a competence, which is clearly redundant. In that case, the main problem is that national definitions of trades have been done years ago, without a clear conceptualisation: it is now very difficult to change these frameworks, applied to thousands of people in the country.

\section{Levels of competences and trades}

Trades can be defined with different levels. Most of the time, these levels were defined by textual labels, like "Beginner, 
Autonomous with assistance, Autonomous, Expert" in Companies $\mathrm{B}$ and $\mathrm{C}$, or "Worker, Professional worker, Companion, Master" in Company F.

Choosing the number of levels for each competence, then their labels is a little bit more tricky. Some companies have chosen to take the same referential for competences and trades (Companies $\mathrm{B}$ and $\mathrm{C}$ ). Others have preferred to describe the competence levels through numbers. A first observation in that case is that scales starting from " 0 " were usually avoided (except in D) in order to decrease the negative psychological effect of holding a competence at level " 0 ". In most cases, 5 levels (1-5) were defined. This is perhaps not a good idea, since it was rapidly noticed that when the assessment of a competence is not clear, "3" seems to be considered as "I do not know", which bears clearly another semantic.

Other companies (Company D and E) tried to associate textual definitions to each level of each competence, which was of course of enormous work. A consequence is that the scale used for each competence may be quite different, e.g. a given level of a competence may be rather basic while the same level of another, more universally hold, may be already quite good. This led to an unexpected problem in Company $\mathrm{E}$ since, as previously explained, labels were also associated to numbers, then aggregated with an average value. We tried to point out that making average values of criteria defined on different scales has no sense, but the company seemed to prefer synthetic indicators than meaningful ones...

Another difficulty of a textual definition of the levels is to be sure that the levels are overlapping, i.e. that somebody having competence A at level 3 also masters levels 1 and 2. The case of a competence assessing the respect of rules in Company D is rather illustrative: the levels were defined as "0- Do only what he wants", "1- Tries to see what is really expected in a rule and applies it", "2- Follows the rules" and "3Understands the rules and may choose not to follow them if needed". A first comment is that the fact that level 2 is better than level 1 can be discussed, but more important, the difference between levels 0 and 3 is mainly a matter of interpretation. In the final version of the referential, level 3 was replaced by a more classical level "can produce rule".

Another difficulty, in Company D, was linked to a competence assessing the "ability to work under stress". The concerned persons argued that accepting this framework was meaning that working under stress is a normal condition of work, which is not acceptable; the competence was removed even if the point addressed is of real relevance for engineers in the present industrial context.

\section{Structure of the competence system}

The structure of the competence system (i.e. how competences are linked to trades and roles), including the types of competences allowing to classify them, is important for the visibility and clarity of the system. In some cases (Company E), a complex structure was defined in order to integrate very different classes of jobs (from the secretary to the head of centre). Similarly, Company F was initially expecting to define a unique framework for workers, secretaries and marketing people, although it was requiring to define different categories of trades, each with a different number of levels. In our opinion, a good balance should be kept between the percentage of employees who can be managed and the complexity of the system: in many cases (B, C, E) we have noticed that more than $50 \%$ of the effort for customising the software was directly linked to extensions of the model concerning less than $10 \%$ of the jobs, all rather marginal regarding the core business of the company. Since the global clarity of the system also depends on its simplicity, we do believe now that having as an objective to describe all the positions in a company is not wise.

\section{Link between trainings and competences}

Many companies asked us to create a precise link between trainings and competences. This link is of course clear for enablings, since a specific training aims at giving an enabling to a person. The case of competences is also clear for "product_competences" like in Companies B and C, since one training again addresses one competence. It is also true for competences close to activities like in Company F. It is much more difficult for general purpose trainings: for instance, what competences will be impacted by a training on mathematics, physics or expression? In our opinion, some generic trainings impact the personal development of persons, and may have indirect influence on very different competences, allowing for instance some persons to finally set in action pieces of knowledge which had been learnt but were not really "possessed". As a consequence, we have always suggested that the person in charge of the feedback after a training should be free to modify any competence level he considers relevant.

\section{CONCLUSION AND PERSPECTIVES}

In the last five years, most of nowadays large companies, and many small ones, have launched ambitious projects aiming at giving a "competence" orientation to the management of their Human Resources.

By describing practical experiences performed in very different companies regarding their size and sector, we have tried to emphasise that quite different needs can be encountered, which need to be addressed with flexibility. Nevertheless, we have also tried to show that defining a consistent competence management framework is not only a long but also a difficult task, which requires to take into account various problems linked to a numerical assessment of human characteristics. In order to cope with this problem, we are currently considering the interest of fuzzy logic as a way to assess competence levels: indeed, fuzzy logic allows to cope with the imprecision of the boundaries between classes, but also permits to work with incomplete data, which would allow to get some information from the system even if all the competences hold by persons or required by processes have not yet been assessed.

\section{REFERENCES}

Amherdt, C.H., Dupuich-Rabasse, F., Emery, Y., Giauque, D., (2000), Compétences collectives dans les 
organisations, Presses universitaires de Laval.

Boucher X., Bonjour, E., Grabot, B., (2007), Formalization and use of competencies for industrial performance optimisation: a survey, Computers in Industry, 58(2).

Davenport, T.H., Prusak, L., (1998), The Knowledge Creating Company. Working Knowledge, Harvard Business Review, November-December, USA.

Franchini, L., Caillaud, E., Nguyen, Ph., Lacoste, G., (1999), Planning and scheduling competences: towards a human resource management in manufacturing systems, Int. Journal of Agile Manufacturing, 2(2)..

Harzallah, M., Vernadat, F., (1999), Human resource competency management in enterprise engineering, 14th IFAC world congress of Information Control in Manufacturing, Beijing, China, July 5-9.

Houe, R., Grabot, B., Geneste, L., (2006), Competence Management For Business Integration, INCOM'06, Saint Etienne, May 17-19.

Kadrou Y., Najid, N., (2008), Multi-mode Resource Constrained Project Scheduling Problem with resource flexibility, Journal of Operations and Logistics, accepted 2008.

Katz, R., Kahn, R.L., (1966), The Social Psychology of Organizations, Wiley \& Sons.

Mc Clelland, D., (1973), Testing for Competence Rather than Intelligence, American Psychologist.
Mintzberg,. H., (1973), The structuring of organisations, Prentice Hall.

Orlicky, J., Plossl, G., (1994), Orlicky's Material Requirement Planning, McGraw Hill Text, 2nd Edition.

Paradeise, C., Lichtenberger, Y., (2001), Compétence, compétences, Sociologie du travail, Editions Scientifiques et Médicales, Elsevier SAS, 43.

Pilbeam, S., Corbridge, M., (2002), People Resourcing HRM in Practice, Prenctice-Hall, 2nd Edition.

Sanchez, R. et al. (1996), Dynamics of Competence-based Competition, Elsevier Science Ltd.

Singh, B., (1992), Interconnected Roles (IR), A coordination Model, MCC Technical Report.

Tsuchiya, S., (1993), Improving knowledge creation ability through organizational learning, International Symposium on the Management of Industrial and Corporate Knowledge, UTC Compiègne, France, October 27-28.

Vaudelin, J.P., (2002). La compétence collective en quête de significations, 1st Conference GCCGI, Nantes, December 12-13.

Wustermann, L., (2001), Recruitment, retention and return in the NHS, Health Service Report 32, autumn.

Zarifian, P., (2002), La politique de la compétence et l'appel aux connaissances dans la stratégie d'entreprise, 1st Conference GCCGI, Nantes, December 12-13. 